\title{
INCORPORATING RELATIVISTIC KINEMATICS FOR THE DESCRIPTION OF LIGHT QUARK SYSTEMS
}

\author{
V. Lengyel ${ }^{\dagger}$, V. Rubish ${ }^{\dagger}$, Yu. Fekete ${ }^{\dagger}$, S. Chalupka ${ }^{\dagger \dagger}$, M. Salak ${ }^{\dagger \dagger}$ \\ ${ }^{\dagger}$ Departament of Theoretical Physics, Uzhgorod State University, \\ 32 Voloshyna Str., UA-294000, Uzhhorod, Ukraine \\ ${ }^{\dagger \dagger}$ Departament of Theoretical Physics and Geophysics, P. J. Safarik University, \\ Moyzesova 16, 04154 Kosice, Slovak Republic \\ ${ }^{\dagger \dagger}$ Departament of Physics, Presov University, \\ 17 Novembra, 08009 Presov, Slovak Republic
}

(Received July 17, 1997)

\begin{abstract}
Different ways of taking into account the relativistic kinematics for the description of both light and heavy quarkonia are studied. The results obtained show that the application of usually used quark-antiquark potentials with the incorporation of the relativistic kinematics allows to obtain quite good description of all the experimental data concerning meson masses without introducing new arbitrary parameters.
\end{abstract}

Key words: quark, potential model, Dirac equation, mesons.

PACS number(s): 12.40.-y, 12.90.+b, 14.40.-n

Successful application of potential models to the description of a few-quark systems is seriously invalidated by its outspoken nonrelativistic character. The very problem of relativistic description of interaction of several particles is not solved fully yet. The current situation concerning the application of quasi-relativistic ideas to the abovementioned problem is reviewed in [1].

A very promising approach to the solution of this problem in general is suggested by Gaida and his collaborators [2], but incorporating spin here still needs further elaboration. In the meantime at least partial solution of this problem was suggested by P. Bogolyubov [3]; and I. Todorov [4] and later developed by Predazzi et. al. [5-7]. Namely they suggest to start with the relativistic expression for energy $E$ of a two-particle system

$$
E=\sqrt{\mathbf{p}_{\mathbf{1}}^{2}+M^{2}}+\sqrt{\mathbf{p}_{\mathbf{1}}^{2}+m^{2}} .
$$

Here we use the $c=h=1$ system of units, we shall put $\mathbf{p}_{\mathbf{1}}=-\mathbf{p}_{\mathbf{2}}=\mathbf{p}$, which is quark momentum in c.m. system, and $M, m$ are the masses of quark and antiquark. This expression will allow us to obtain the masses of the bound quark-antiquark system incorporating relativistic kinematics, and to explain hopefully such interesting feature as Regge-trajectories of particles. No full description of both light-quark and heavy-quark Reggetrajectories are obtained yet within the framework of the same potential with the same parameters. (1)

By quite simple algebraic transformations we get from

$$
\left(\frac{E^{2}+m^{2}-M^{2}}{2 E}\right)^{2}=\mathbf{p}^{2}+m^{2}
$$

In the full agreement with the Dirac linearisation of Klein-Gordon-Fock equation we get

$$
\frac{E^{2}+m^{2}-M^{2}}{2 E}=\boldsymbol{\alpha} \mathbf{p}+\beta m
$$

where $\boldsymbol{\alpha}=\left(\begin{array}{cc}0 & \boldsymbol{\sigma} \\ \boldsymbol{\sigma} & 0\end{array}\right), \beta=\left(\begin{array}{cc}I & 0 \\ 0 & -I\end{array}\right)$ are the usual Dirac matrices , $\boldsymbol{\sigma}$ being the usual Pauli matrices, or in the fully relativistic form

$$
\left(\gamma_{\mu} p_{\mu}-i m\right) \Psi(\mathbf{r})=0
$$

The definition of $\gamma$-matrices is taken from [8]. One of advantages of this form is that it allows one to discriminate between different Lorentz-character of interaction, this discrimination being completely lost in any other forms of the equation of motion. Namely, the interaction potential can be either of a scalar form, in which case it can be introduced by substituting $m \rightarrow m+S(r)$, or it can by the 4 -th component of vector in which case one could have

$$
\mathbf{p} \rightarrow \mathbf{p}-\frac{e}{c} \mathbf{A}, p_{0} \rightarrow E-e \varphi \rightarrow W-V(r)
$$

where in our case

$$
W=\frac{E^{2}+m^{2}-M^{2}}{2 E}
$$

and in case of equal masses, evidently $W=E / 2, E$ being the total energy of a 2-quark system, $S(r)$ and $V(r)$ are clearly indicating the scalar or vector character of potential, respectively.

For reaching our goal and for simplifying the calculations we shall use the averaged version or the interaction potential, namely we can put 


$$
U(r)=\frac{1}{2}[\beta S(r)+I V(r)]
$$

which is of the type, previously suggested by Kukulin, Loyola and Moshinsky [9].

Then the equivalent of the Dirac equation acquires the following form

$$
\left(\frac{E^{2}+m^{2}-M^{2}}{2 E}\right)\left(\begin{array}{l}
\Psi_{1} \\
\Psi_{2}
\end{array}\right)=\left(\boldsymbol{\alpha} \mathbf{p}+\beta m+\frac{1}{2}[\beta S(r)+I V(r)]\right)\left(\begin{array}{l}
\Psi_{1} \\
\Psi_{2}
\end{array}\right) .
$$

This is exactly the relativistic version of two-body system with the masses $m$ and $M$ and the averaged interaction potential between them. Let us restrict ourselves to the case when $m=M$. In this case (5) acquires the form

$$
\begin{aligned}
& \frac{E}{2} \Psi_{1}=\boldsymbol{\sigma} \cdot \mathbf{p} \Psi_{2}-\operatorname{Im} \Psi_{1}-\frac{1}{2} S \Psi_{1}+\frac{1}{2} I V \Psi_{1}, \\
& \frac{E}{2} \Psi_{2}=\boldsymbol{\sigma} \cdot \mathbf{p} \Psi_{1}-\operatorname{Im} \Psi_{2}-\frac{1}{2} S \Psi_{2}+\frac{1}{2} I V \Psi_{2} .
\end{aligned}
$$

After expressing $\Psi_{2}$ from the second equation of (6) and substituting it into the first one we obtain

$$
\begin{aligned}
(E-V)^{2} \Psi_{1} & =\left[4 p^{2}+4 m^{2}+4 m S+S^{2}\right] \Psi_{1} \\
& =\left[4 p^{2}+4\left(m+\frac{S}{2}\right)^{2}\right] \Psi_{1} .
\end{aligned}
$$

The same result is obtained if one makes the substitution $m \rightarrow m+\frac{S}{2}, E \rightarrow E-V$ (see for comparison [5]).

Lichenberg, Predazzi et al called the eq (7) the Krolikowsky-type equation. In the nonrelativistic approximation

$$
E \sim 2 m+\frac{P^{2}}{m}+S(r)+V(r)
$$

or, in other words, is the full kinetic energy of two par- ticles and interaction energy between them. Below we shall solve equation (7) with the full interaction potential between quarks. As it is seen from (7) in obtaining the final result we omit the terms of an order of $1 / c^{2}$ here which means neglecting the spin-orbital Minteraction and Darwin term. In this respect one could say that the Dirac equation is reduced to the Klein-Gordon-Fock equation but as we have mentioned above the $\boldsymbol{\sigma} \cdot \mathbf{L}$-term can be easily restored, leading, by the way, to interesting conclusions. Namely, as it was shown in [10] exactly along this way the problem of falling on the center of the particle due to the $1 / r^{3}$ type behaviour of the spinorbital term is removed. Besides the Lorentz-structure of the potential can be clearly identified in this case. In addition let us consider also the case, suggested in [9], i. e. the potential

$$
U(r)=\frac{1}{2}(\beta+I)(S+V) .
$$

In this case no spin-orbital terms will be present in any order of $1 / c^{2}$ expansion. As an example of working the relativistic kinematics let us consider a pure oscillator potential

$$
S+V=\frac{1}{2}\left(A r^{2}+V_{0}\right)
$$

The factor $1 / 2$ secures the coincidence with a nonrelativistic limit. Indeed from (9) one obtains

$$
\left[p^{2}+\left(\frac{E}{2}+m\right)\left(\frac{1}{2} A r^{2}+\frac{1}{2} V_{0}\right)-\left(\frac{E^{2}}{4}-m^{2}\right)\right] \Psi_{1}=0
$$

Transferring to operators and carrying out the substitutions for the unknown function $\Psi_{1}=\frac{\Psi(r)}{r}$ one obtains the equation for relativistic isotropic oscillator

$$
\left[\frac{d^{2}}{d r^{2}}-\frac{l(l+1)}{r^{2}}-\left(\frac{E}{2}+m\right) \cdot \frac{1}{2} A r^{2}+\frac{E^{2}}{4}-m^{2}-\left(\frac{E}{2}+m\right) \cdot \frac{1}{2} V_{0}\right] \Psi(r)=0
$$

Now with the standard change of variables $\sqrt{\left(\frac{E}{2}+m\right) \frac{1}{2} A} \cdot r^{2}=x^{2}$ one obtains 


$$
\left[\frac{d^{2}}{d x^{2}}-\frac{l(l+1)}{x^{2}}-x^{2}+\frac{E^{2} / 4-m^{2}-\frac{1}{2} V_{0}\left(\frac{E}{2}+m\right)}{\sqrt{\left(\frac{E}{2}+m\right) \frac{A}{2}}}\right] \Psi(x)=0 .
$$

The physical solution of (12) is satisfied, when

$$
\begin{aligned}
\frac{E^{2}}{4}-m^{2} & =\sqrt{\frac{A}{2} \cdot \frac{E+2 m}{2}} \cdot(4 N+2 l+3) \\
& +\frac{V_{0}(E / 2+m)}{2}
\end{aligned}
$$

or

$$
\frac{E}{2}-m=\sqrt{\frac{A}{E+2 m}}(4 N+2 l+3)+\frac{V_{0}}{2} .
$$

In the nonrelativistic limit when $E \sim 2 m$ one has

$$
E \approx 2 m+\sqrt{\frac{A}{m}}(4 N+2 l+3)+V_{0}
$$

in full accordance with the nonrelativistic case (see, e. q. [11]).

As we see from (14) incorporating the relativistic kinematics leads to a non-linear dependence of $E(l)$ in much better accordance with experimental Regge-trajectory contrary to the linear non-relativistic case (15). The relevant calculations borrowed from [11] are shown in Table 1. As for the evaluation of the results following from (7) several possibilities open here even if one restricts himself by considering only the oscillator part of the potential. Namely in reducing $(7)$ to second-order differential equation and restricting in $(7)\left(m+\frac{S}{2}\right)^{2} \sim m^{2}+\frac{S^{2}}{4}$ by the first and the third terms for Cornell potential one obtains the familiar oscillator-type solution

$$
M=\sqrt{2 k \cdot(4 N+2 l+3)+4 m^{2}}+V_{0},
$$

but taking into account the second term $k m r$ too needs numerical calculations

$$
\frac{d^{2} x(\xi)}{d \xi^{2}}-\left[\frac{l(l+1)}{\xi^{2}}+\xi^{2}+\frac{2 \sqrt{2}}{\sqrt{k}} \cdot m \xi-\left(\frac{E^{2}}{4-m^{2}}\right) \cdot \frac{2}{k}\right] x(\xi)=0 .
$$

All these evaluations have been carried out by us and the results are summarized in Table (1). The main conclusion is that relativistic kinematics is essential, but the second conclusion is that potential (9) rather than potential (4) is the most appropriate. Also a nontrivial conclusion is that the term $\mathrm{kmr}$ does not play an essential role in the considered energy region. The assumption of this possibility was expressed already in [5]. But for obtaining realistic results we have to consider in potential also one-gluon-term in addition to many-gluon exchange terms. Therefore we choose the following forms of quark-antiquark potential

$$
\begin{aligned}
& V+S=-\frac{\alpha}{r}+A r^{2}, \\
& V+S=-\frac{\alpha}{r}+k r \\
& V+S=\frac{g^{2}}{6 \pi \mu}\left(1-e^{-\mu r}\right)-\frac{16 \pi}{25} \cdot \frac{e^{-k r}}{r \cdot \ln \left(b+\left(\frac{1}{\Lambda r}\right)^{2}\right)} .
\end{aligned}
$$

The first of these potentials is chosen because its confinement part $A r^{2}$ allows to obtain a direct analytical solution, while $\frac{\alpha}{r}$ (one-gluon exchange term) can be considered by the perturbation method or by the configuration interaction approach (CIA). The results obtained with this potential are reviewed in [11]. The second potential is a well-known Cornell potential [12], and its advantage is a very good description of heavy-quark systems and seems to be QCD motivated. The last one is also more or less QCD-motivated and is based on assumption that the scattering amplitude has a double pole and a cut [13]. Its main distinction from other potentials is screening the interaction at large distances which seems to be a very credible feature. There were some works (e. g. $[14,15])$ in which an attempt of describing the light-quark systems was made but they had only a limited success, since obtaining good description in this case demanded a change of parameters. In addition doubts remained concerning the applicability of the whole scheme to evidently quite a relativistic case. Therefore we believed that to pursue the 
course of incorporating the relativistic kinematics would be quite interesting and didactic.

Recently a very promising approach to the problem of relativistic description of many-particle systems was elaborated along with the ideas presented in [2] by
Tretyak and Shpitko $[16,17,18]$. They used the Weyl quantization method and succeeded in solving the problem for the relativistic oscillator coupling between two particles. Namely they obtained the following expression for the mass $M$ of a two-particle system

$$
M=\sqrt{\left(\sum m_{q}+\sqrt{\frac{A}{m_{q}}} \cdot(4 N+2 l+3)\right)^{2}+\frac{A}{m_{q}}}+V_{0}
$$

if we express (19) in form of string tension $A$ and generalize their results to our boundary conditions of isotropic oscillator. It is interesting that the results similar to (19) for the $M^{2}$ - operator were obtained in the relativistic approach by Ishida-Oda based on a special assumption of the covariant relativistic approach. Even the numerical values of parameters of Ishida-Oda [19] are close to the results of [9]. Their $k$ goes to $A=0.05 \mathrm{GeV}^{3}$ which is of the same order as is to be used in (17). A more precise comparison is impossible because of the ambiguity of their other parameters.

So we are left with four most realistic from our point view possibilities, of calculating the masses according to (18 a,b,c) and (19).

To obtain the masses of a multi-quark system according to these expressions it is necessary to define the values of the parameters. The masses of bottom and charmed quarks were taken to be as usually in quark models $m_{b}$ $=5.1-5.05 \mathrm{GeV}, m_{c}=1.75-1.675 \mathrm{GeV}, m_{u}=0.33 \mathrm{GeV}$, $A=0.04 \mathrm{GeV}^{3}, V_{0}=-0.71 \mathrm{GeV}$ for (14). For potential (18a) we choose the parameters: $\alpha_{u}=0.5, \alpha_{c}=$ 0.386, $\alpha_{b}=0.3$, which follow from the well-known expression for the asymptotic freedom $\alpha(r)$ at $\Lambda=140$ $\mathrm{MeV}$ according to the asymptotic freedom [1], $V_{0}=-$ $0.527 \mathrm{GeV}$ and same value of $A$. Calculations according to (18b) were carried out with $k=0.305 \mathrm{GeV}^{2}, V_{0}$ $=-0.908 \mathrm{GeV}$. In order to be able to compare the results of light mesons count with CJP-calculations (18c) of heavy quarkonia [18] we have used parameters very close to their values, namely: $\frac{g^{2}}{6 \pi}=0.3795 \mathrm{GeV}^{2}, \mu=$ $0.054 \mathrm{GeV}, K=0.75 \mathrm{GeV}, \Lambda \stackrel{6 \pi}{=} 0.35 \mathrm{GeV}, b=4, V_{0}=$ $-1.103 \mathrm{GeV}$. As for the string-constant $A$ in (17) it was taken to be equal $0.02 \mathrm{GeV}^{3}$, and $V_{0}=-0.652 \mathrm{GeV}$. In (16) $k=0.365 \mathrm{GeV}^{2}, V_{0}=-0.85 \mathrm{GeV}, m_{u}=0.33 \mathrm{GeV}$. In (17) $k=0.365 \mathrm{GeV}^{2}, V_{0}=-1.165 \mathrm{GeV}$. In (19) $A=$ $0.01, V_{0}=-0.436 \mathrm{GeV}$.

The whole variegated array of parameters is reduced actually to the following one $A=0.02 \div 0.04 \mathrm{GeV}^{3}$ for the oscillator and $k=0.03 \div 0.37 \mathrm{GeV}^{2}$ for the Cornell potential, while for all forms of potentials $V_{0}$ varies within $20 \%$ around the value $V_{0} \sim-1 \div-0.8 \mathrm{GeV}$. Actually if one takes into account the factor $1 / 2$ in the definition
$(9,10)$ of potential then real value of these parameters will be $0.01-0.02 \mathrm{GeV}^{3}$ for $A$ and $\frac{1}{(2.58)^{2}} \div \frac{1}{(2.32)^{2}}$ for $k$. Which are to be compared with the corresponding values used previously in nonrelativistic approximation for heavy mesons $A=0.014 \mathrm{GeV}^{3}[11]$ and $k=\frac{1}{(2.34)^{2}}$ [12], then one comes to the conclusion that finally with incorporating relativistic kinematics we can state that both heavy and light mesons are simultaneously described without upsetting all the previous calculations.

The results of calculations together with the experimental data are shown in tables (1-6). Experimental values were taken from [20]. For choosing the best parameters the $\chi^{2}$-criterion was used with the definition:

$$
\chi^{2}=\frac{1}{N-n-1} \cdot \sum_{i}\left(\frac{M_{\mathrm{TH}}-M_{\mathrm{EXP}}}{\Delta}\right)_{i}^{2}
$$

the minimum of $\chi^{2}$ was searched for the confinement parameters in (18a)-(18c) and (19). Here $N$ is the number of meson experimental points, $n$ is the number of parameters in our case we considered them to be equal to two, namely the confinement parameter and $V_{0}, \Delta$ is the error in the definition of the experimental mass $M_{\mathrm{EXP}}$ of a two-quark system since $V_{0}$ was chosen to match the experimental value of the ground-state mass, we are actually left only with one adjustable parameter $A$ (or $k$ ). Since we do not include $\sigma L$-forces we had to take the average center of gravity value of $\mathrm{P}$-resonances, which was calculated according to the formula

$$
M_{\mathrm{COG}}=\frac{\sum(2 J+1) \cdot M_{J}}{\sum(2 J+1)} .
$$

As one can see from both radial and orbital excitation calculations the best description is given by Cornell potential and CJP-potential. Especially very surprising is an excellent description of $u \bar{u}$ - data by Cornell potential $\left(\chi^{2}=1.8\right)$. It is very consoling that not only lower but also higher both radial and orbital excitations are in reasonable agreement with experimental data. One more 
remark is to be made concerning large values of $\chi^{2}$ for heavy mesons. We would like to point out, that these large numbers are due to the extremely precise definition of these masses. While masses are defined with the error order of $\pm 0.3 \mathrm{MeV}$ contemporary theory hardly pretends to precision larger than $5 \mathrm{MeV}$ (in comparison, say to $M_{2 S}=10023 \mathrm{MeV}$ ). If one evaluates the $\chi^{2}$ for $\mathrm{c} \overline{\mathrm{c}}$ and $\mathrm{b} \overline{\mathrm{b}}$ calculated by Cornell or CJP-potential ([12], [13]) one obtains $\chi^{2}=1.8,\left(\chi^{2}=1.36 \cdot 10^{5}\right) ; \chi^{2}=14$, $\left(\chi^{2}=1.3 \cdot 10^{6}\right)$ respectively, which is of the same order as shown in tables 2-4. The Regge-trajectory for twoquark systems were studied in many works (see, e. q. [1], [14], [19], [23]) within the analytical approach. But this Ansatz does not give a satisfactory description of heavy quark systems with the same parameters. The same situation can be demonstrated in the reverse direction Cornell potential, as it was shown by Eichten et al, [12], gives a quite good description of $c \bar{c}$ and $b \bar{b}-$ systems but is much worse in explaining $\rho$-meson (see tables $2-6$ ). A certain test of the models can be carried out by comparing the calculation concerning first radial excitation of $\rho^{\prime}$-meson. Previously the mass equal to $1600 \mathrm{MeV}$ was attributed to this meson, and this seemed to be con- firmed by the nonrelativistic power-law calculations (see [21], [22]). The currently accepted experimental value seems to be rather close to $1465 \mathrm{MeV}$ [20], which contradicts these calculations. One might suspect that this discrepancy may be due to the relativistic effects. Our calculations show that it is not so. Therefore we maintain that the appropriation of $1465 \mathrm{MeV}$ to $\rho^{\prime}$-meson is to be revised. It is worthwhile to remark, that the first who pointed to this circumstance was Lichtenberg, Perdazzi et al [5]. The CJP-potential value turns out to be closest to experiment for higher values of excitations (see tables $4-5$ ). It seems that the screening does play some role here. This conclusion perfectly coincides with the one, obtained in [24] where a phenomenological screened confining potential was used. Therefore it is not a trivial fact that the CJP-potential gives not only quite a good description of the mass spectrum of a heavy quark system, but also a good description of light quark system. And finally a remark about Spitko-Tretyak's results for the oscillator potential. It seems that relativistic effects are included here correctly but real results can be obtained only when a one-gluon term $\left(-\frac{\alpha}{r}\right)$ is included into the scheme.

\begin{tabular}{|l|l|l|l|l|l|l|}
\hline state & designation & $\begin{array}{l}M_{\mathrm{EXP}} \\
\mathrm{GeV}\end{array}$ & $\begin{array}{l}\text { Nonreal. }[11] \\
\mathrm{GeV}\end{array}$ & $\begin{array}{l}M_{\mathrm{TH}}(14) \\
\mathrm{GeV}\end{array}$ & $\begin{array}{l}M_{\mathrm{TH}}(16) \\
\mathrm{GeV}\end{array}$ & $\begin{array}{l}M_{\mathrm{TH}}(17) \\
\mathrm{GeV}\end{array}$ \\
\hline $1 \mathrm{~S}$ & $\rho 1^{+}\left(1^{--}\right)$ & $0.768 \pm 0.0005$ & 0.77 & 0.77 & 0.77 & 0.77 \\
\hline $1 \mathrm{P}$ & ${ }^{3} \mathrm{P}_{\mathrm{COG}}^{*}$ & $1.262 \pm 0.03$ & 1.166 & 1.198 & 1.171 & 1.222 \\
\hline $2 \mathrm{~S}$ & $\rho 1^{+}\left(1^{--}\right)$ & $1.465 \pm 0.025$ & 1.562 & 1.58 & 1.505 & 1.552 \\
\hline $2 \mathrm{P}$ & $a_{2} 1^{-}\left(2^{++}\right)$ & $1.935 \pm 0.015$ & 1.958 & 1.93 & 1.796 & 1.857 \\
\hline $3 \mathrm{~S}$ & $\rho 1^{+}\left(1^{--}\right)$ & $2.15 \pm 0.01$ & 2.353 & 2.259 & 2.06 & 2.118 \\
\hline $1 \mathrm{D}$ & $\rho_{3} 1^{+}\left(3^{--}\right)$ & $1.691 \pm 0.013$ & 1.562 & 1.58 & 1.505 & 1.572 \\
\hline $2 \mathrm{D}$ & $\rho_{3} 1^{+}\left(3^{--}\right)$ & $2.25 \pm 0.01$ & 2.353 & 2.259 & 2.06 & 2.13 \\
\hline $1 \mathrm{~F}$ & $a_{4} 1^{-}\left(4^{++}\right)$ & $2.027 \pm 0.036$ & 1.958 & 1.93 & 1.796 & 1.873 \\
\hline $1 \mathrm{G}$ & $\rho_{5} 1^{+}\left(5^{--}\right)$ & $2.350 \pm 0.015$ & 2.353 & 2.259 & 2.06 & 2.45 \\
\hline $1 \mathrm{H}$ & $a_{6} 1^{-}\left(6^{++}\right)$ & $2.45 \pm 0.13$ & 2.75 & 2.57 & 2.3 & 2.393 \\
\hline$\chi^{2}$ & & & 90 & 78 & $1.86 \cdot 10^{2}$ & 68 \\
\hline
\end{tabular}

Table 1. Comparison of different averaged potentials with the $u \bar{u}-$ experimental data.

\begin{tabular}{|l|l|l|l|l|l|l|}
\hline State & designation & $\begin{array}{l}M_{\mathrm{EXP}} \\
\mathrm{GeV}\end{array}$ & $\begin{array}{l}M_{\mathrm{TH}} \\
\mathrm{GeV}\end{array}$ & $\begin{array}{l}M_{\mathrm{TH}}(18 \mathrm{~b}) \\
\mathrm{Gev}\end{array}$ & $\begin{array}{l}M_{\mathrm{TH}}(18 \mathrm{c}) \\
\mathrm{GeV}\end{array}$ & $\begin{array}{l}M_{\mathrm{TH}} \\
\mathrm{GeV}\end{array}$ \\
\hline $1 \mathrm{~S}$ & $\rho 1^{+}\left(1^{--}\right)$ & $0.768 \pm 0.0005$ & 0.77 & 0.77 & 0.77 & 0.768 \\
\hline $1 \mathrm{P}$ & ${ }^{3} \mathrm{P}_{\mathrm{COG}}^{*}$ & $1.262 \pm 0.03$ & 1.26 & 1.296 & 1.3 & 1.119 \\
\hline $2 \mathrm{~S}$ & $\rho 1^{+}\left(1^{--}\right)$ & $1.465 \pm 0.025$ & 1.609 & 1.573 & 1.561 & 1.472 \\
\hline $2 \mathrm{P}$ & $a_{2} 1^{-}\left(2^{++}\right)$ & $1.935 \pm 0.015$ & 2.003 & 1.932 & 1.889 & 1.824 \\
\hline $3 \mathrm{~S}$ & $\rho 1^{+}\left(1^{--}\right)$ & $2.15 \pm 0.01$ & 2.3 & 2.155 & 2.103 & 2.177 \\
\hline $1 \mathrm{D}$ & $\rho_{3} 1^{+}\left(3^{--}\right)$ & $1.691 \pm 0.013$ & 1.665 & 1.689 & 1.687 & 1.472 \\
\hline $2 \mathrm{D}$ & $\rho_{3} 1^{+}\left(3^{--}\right)$ & $2.25 \pm 0.01$ & 2.348 & 2.235 & 2.1845 & 2.177 \\
\hline $1 \mathrm{~F}$ & $a_{4} 1^{-}\left(4^{++}\right)$ & $2.037 \pm 0.036$ & 2.03 & 2.021 & 2.003 & 1.824 \\
\hline $1 \mathrm{G}$ & $\rho_{5} 1^{+}\left(5^{--}\right)$ & $2.350 \pm 0.015$ & 2.366 & 2.312 & 2.275 & 2.177 \\
\hline $1 \mathrm{H}$ & $a_{6} 1^{-}\left(6^{++}\right)$ & $2.45 \pm 0.13$ & 2.685 & 2.576 & 2.514 & 2.530 \\
\hline$\chi^{2}$ & & & 53.3 & 1.8 & 19.6 & 84 \\
\hline
\end{tabular}

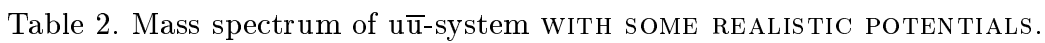




\begin{tabular}{|l|l|l|l|l|l|l|}
\hline State & designation & $\begin{array}{l}M_{\mathrm{EXP}} \\
\mathrm{GeV}\end{array}$ & $\begin{array}{l}M_{\mathrm{TH}}(14) \\
\mathrm{GeV}\end{array}$ & $\begin{array}{l}M_{\mathrm{TH}}(18 \mathrm{a}) \\
\mathrm{GeV}\end{array}$ & $\begin{array}{l}M_{\mathrm{TH}}(18 \mathrm{~b}) \\
\mathrm{GeV}\end{array}$ & $\begin{array}{l}M_{\mathrm{TH}}(18 \mathrm{c}) \\
\mathrm{GeV}\end{array}$ \\
\hline $1 \mathrm{~S}$ & $\mathrm{~J} / \Psi 0^{-}\left(1^{--}\right)$ & $3.096 \pm 0.00009$ & 3.136 & 3.079 & 3.0657 & 2.902 \\
\hline $1 \mathrm{P}$ & $\left.\chi_{\mathrm{c} 10^{+}\left(1^{++}\right)}\right)$ & $3.51 \pm 0.00012$ & 3.418 & 3.452 & 3.519 & 3.424 \\
\hline $1 \mathrm{D}$ & $\Psi ?^{?}\left(1^{--}\right)$ & $3.770 \pm 0.0025$ & 3.692 & 3.758 & 3.854 & 3.789 \\
\hline $2 \mathrm{~S}$ & $\Psi 0^{-}\left(1^{--}\right)$ & $3.688 \pm 0.0001$ & 3.692 & 3.688 & 3.745 & 3.662 \\
\hline $2 \mathrm{D}$ & $\Psi ?^{?}\left(1^{--}\right)$ & $4.159 \pm 0.02$ & 4.215 & 4.296 & 4.324 & 4.252 \\
\hline $3 \mathrm{~S}$ & $\Psi ?^{?}\left(1^{--}\right)$ & $4.04 \pm 0.01$ & 4.215 & 4.235 & 4.25 & 4.162 \\
\hline $3 \mathrm{D}$ & $\Psi ?^{?}\left(1^{--}\right)$ & $4.415 \pm 0.006$ & 4.71 & 4.793 & 4.734 & 4.629 \\
\hline$\chi^{2}$ & & & $2.43 \cdot 10^{5}$ & $1 \cdot 10^{5}$ & $1.36 \cdot 10^{5}$ & $1.82 \cdot 10^{6}$ \\
\hline
\end{tabular}

Table 3. The same for c $\bar{c}$-system.

\begin{tabular}{|l|l|l|l|l|l|l|}
\hline State & designation & $\begin{array}{l}M_{\mathrm{EXP}} \\
\mathrm{GeV}\end{array}$ & $\begin{array}{l}M_{\mathrm{TH}}(14) \\
\mathrm{GeV}\end{array}$ & $\begin{array}{l}M_{\mathrm{TH}}(18 \mathrm{a}) \\
\mathrm{GeV}\end{array}$ & $\begin{array}{l}M_{\mathrm{TH}}(18 \mathrm{~b}) \\
\mathrm{GeV}\end{array}$ & $\begin{array}{l}M_{\mathrm{TH}}(18 \mathrm{c}) \\
\mathrm{GeV}\end{array}$ \\
\hline $1 \mathrm{~S}$ & $\Upsilon ?^{?}\left(1^{--}\right)$ & $9.460 \pm 0.00022$ & 9.655 & 9.565 & 9.42 & 9.246 \\
\hline $1 \mathrm{P}$ & ${ }^{3} \mathrm{P}_{\mathrm{COG}}^{*}$ & $9.892 \pm 0.0007$ & 9.83 & 9.85 & 9.83 & 9.758 \\
\hline $2 \mathrm{~S}$ & $\Upsilon ?^{?}\left(1^{--}\right)$ & $10.023 \pm 0.00031$ & 10.004 & 9.985 & 9.99 & 9.949 \\
\hline $2 \mathrm{P}$ & ${ }^{3} \mathrm{P}_{\mathrm{COG}}^{*}$ & $10.268 \pm 0.00057$ & 10.178 & 10.219 & 10.261 & 10.246 \\
\hline $3 \mathrm{~S}$ & $\Upsilon ?^{?}\left(1^{--}\right)$ & $10.355 \pm 0.0005$ & 10.346 & 10.357 & 10.3993 & 10.393 \\
\hline $4 \mathrm{~S}$ & $\Upsilon ?^{?}\left(1^{--}\right)$ & $10.58 \pm 0.0035$ & 10.684 & 10.711 & 10.743 & 10.745 \\
\hline $5 \mathrm{~S}$ & $\Upsilon ?^{?}\left(1^{--}\right)$ & $10.865 \pm 0.008$ & 11.015 & 11.055 & 11.049 & 11.044 \\
\hline $6 \mathrm{~S}$ & $\Upsilon ?^{?}\left(1^{--}\right)$ & $11.019 \pm 0.008$ & 11.345 & 11.391 & 11.328 & 11.312 \\
\hline$\chi^{2}$ & & & $1.28 \cdot 10^{5}$ & $3.68 \cdot 10^{4}$ & $1 \cdot 10^{4}$ & $2.1 \cdot 10^{5}$ \\
\hline
\end{tabular}

Table 4. The same for $\mathrm{b} \bar{b}$-system.

\begin{tabular}{|l|l|l|l|}
\hline State & designation & $\begin{array}{l}M_{\mathrm{EXP}} \\
\mathrm{GeV}\end{array}$ & $\begin{array}{l}M_{\mathrm{TH}}(19) \\
\mathrm{GeV}\end{array}$ \\
\hline $1 \mathrm{~S}$ & $\mathrm{~J} / \Psi 0^{-}\left(1^{--}\right)$ & $3.096 \pm 0.00009$ & 3.253 \\
\hline $1 \mathrm{P}$ & $\chi_{\mathrm{c} 10^{+}\left(1^{++}\right)}$ & $3.51 \pm 0.00012$ & 3.405 \\
\hline $1 \mathrm{D}$ & $\Psi ?^{?}\left(1^{--}\right)$ & $3.77 \pm 0.0025$ & 3.597 \\
\hline $2 \mathrm{~S}$ & $\Psi 0^{-}\left(1^{--}\right)$ & $3.688 \pm 0.0001$ & 3.597 \\
\hline $2 \mathrm{D}$ & $\Psi ?^{?}\left(1^{--}\right)$ & $4.159 \pm 0.02$ & 3.901 \\
\hline $3 \mathrm{~S}$ & $\Psi ?^{?}\left(1^{--}\right)$ & $4.04 \pm 0.01$ & 3.901 \\
\hline $3 \mathrm{D}$ & $\Psi ?^{?}\left(1^{--}\right)$ & $4.415 \pm 0.006$ & 4.205 \\
\hline$\chi^{2}$ & & & $1.3 \cdot 10^{6}$ \\
\hline
\end{tabular}

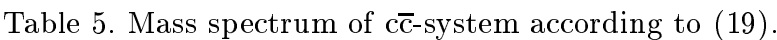

\begin{tabular}{|l|l|l|l|}
\hline State & designation & $\begin{array}{l}M_{\mathrm{EXP}} \\
\mathrm{GeV}\end{array}$ & $\begin{array}{l}M_{\mathrm{TH}} \\
\mathrm{GeV}\end{array}$ \\
\hline $1 \mathrm{~S}$ & $\Upsilon ?^{?}\left(1^{--}\right)$ & $9.460 \pm 0.00022$ & 9.560 \\
\hline $1 \mathrm{P}$ & ${ }^{3} \mathrm{P}_{\mathrm{COG}}^{*}$ & $9.892 \pm 0.0007$ & 9.689 \\
\hline $2 \mathrm{~S}$ & $\Upsilon ?^{?}\left(1^{--}\right)$ & $10.023 \pm 0.00031$ & 9.799 \\
\hline $2 \mathrm{P}$ & ${ }^{3} \mathrm{P}_{\mathrm{COG}}^{*}$ & $10.268 \pm 0.00057$ & 9.869 \\
\hline $3 \mathrm{~S}$ & $\Upsilon ?^{?}\left(1^{--}\right)$ & $10.355 \pm 0.0005$ & 9.959 \\
\hline $4 \mathrm{~S}$ & $\Upsilon ?^{?}\left(1^{--}\right)$ & $10.58 \pm 0.0035$ & 10.139 \\
\hline $5 \mathrm{~S}$ & $\Upsilon ?^{?}\left(1^{--}\right)$ & $10.865 \pm 0.008$ & 10.319 \\
\hline $6 \mathrm{~S}$ & $\Upsilon ?^{?}\left(1^{--}\right)$ & $11.019 \pm 0.008$ & 10.499 \\
\hline$\chi^{2}$ & & & $3.9 \cdot 10^{5}$ \\
\hline
\end{tabular}

Table 6. Mass spectrum of b $\bar{b}$-system according to (19).

*) — center of gravity. 
[1] W. Lucha, F. Shöberl, Phys. Rep. 200, 127 (1991).

[2] R. P. Gaida, J. Math. ПPhys. 13, 427 (1982).

[3] P. Bogolyubov, Fiz. Elem. Chastits At. Yadra 3, 144 (1972).

[4] I. Todorov, Phys. Rev. D 3, 2351 (1971).

[5] D. Lichtenberg, W. Namgung, J. Wills, E. Predazzi, Z. Phys. C 41, 615 (1989).

[6] D. B. Lichtenberg, R. Roncaglia, J. Wills, E. Predazzi, M. Rosso, Z. Phys. C 46, 75 (1990).

[7] D. B. Lichtenberg, E. Predazzi, R. Roncaglia, C. Rosseti, Z. Phys. C 40, 357 (1988).

[8] A. S. Davydov, Kvantova Mekhanika (Quantum Mechanics) (Nauka, Moskow, 1973)

[9] V. Kukulin, G. Loyola, M. Moshinsky, Phys. Lett. A 158, 19 (1991)

[10] I. Haysak, A. Shpenik, V. Lengyel, in Proceedings of Hadron Structure - 94, september 19-23, 1994 (Safarik Univ. press, Kosice, 1994), p. 215.

[11] V. Lengyel, V. Makkay, Vid atomiv do kvarkiv (From Atoms to Quarks) Uzhgorod univ. preprint, 1995, see also S. Chalupka, V. Lengyel, M. Salak, Czech. J. Phys. 44, 107 (1994).

[12] E. Eichten, R. Gottfried, Phys. Rev. D 21, 203 (1980), see also S. Godfrey, M. Isgur, Phys. Rev. D 32, 189 (1985).
[13] Z. Chikovani, L. Jenkovsky, F. Paccanoni, Mod. Phys. Lett. A 6, 140 (1991).

[14] M. Fabre de la Ripelle, Phys. Lett. B 205, 97 (1985).

[15] A. M. Badalyan, D. I. Kitoroage and D. S. Pariysky, Sov. J. Nucl. Phys. 46, 226 (1987).

[16] V. Tretyak, V. Shpytko, Ukr. Fiz. Zh. 40, 1250 (1995).

[17] V. Tretyak, V. I. Shpytko, J. Nonlin. Math. Phys. 4, 161 (1997).

[18] A. A. Duviryak, V. I. Tretyak, V. Ye. Shpytko, in Proceedings of the Workshop on Soft Physics "Hadrons-94", Uzhorod, September 7-11, 1994 (Inst. Th. Phys., Kiev, 1994), p. 353.

[19] S. Ishida, M. Oda, Nuovo Cimento A 107, 2510 (1994).

[20] Part. Data Group, Phys. Rev. D, 1 (1996).

[21] M. I. Haysak, V. I. Lengyel, S. Chalupka, M. Salak, in Proceedings of the 12-th European Conference on Fewbody Physics Uzhgorod, June 1-5, 1990 (Uzhgorod University, 1990), p. 257.

[22] M. I. Haysak, V. I. Lengyel, S. Chalupka, M. Salak, Czech. J. Phys. 41, 799 (1991).

[23] A. V. Kholodkov, F. Paccanoni, S. S. Stepanov and R. S. Tutik, J. Phys. C 18, 985 (1992).

[24] D. Yubing, Y. Youwen, W. Yingcai, Energies in multiquark systems for screened potential, preprint IHEP-9257, Beijing.-China.-1992.

\title{
УРАХУВАННЯ РЕЛЯТИВІСТСЬКОЇ КІНЕМАТИКИ ДЛЯ ОПИСУ ЛЕГКИХ КВАРКОВИХ СИСТЕМ
}

\author{
В. Лендьел ${ }^{+}$, В. Рубіш ${ }^{+}$, Ю. Фекете ${ }^{+}$, С. Халупка ${ }^{++}$, М. Салак ${ }^{+++}$ \\ + Ужсгородсъкий державний університет, кафедра теоретичної фізики, \\ вул. Волочина, 32, Ужгород, UA-294000, Украӥна \\ ${ }^{++}$Університет ім. Шафарика, кафедра теоретичної фізики та геофізики, \\ вул. Мойзесова, 16, Кошіче, 041 54, Словаччина \\ +++ Прлшівсъкий університет, кафедра фізики, \\ вул. 17 грудня, Пряшів, 080 09, Словаччина
}

Вивчено різні способи врахування релятивістської кінематики для опису спектра мас двокваркових систем. Показано, що існують способи врахування релятивістської кінематики, які дозволяють дати дуже добрий опис спектра мас легких кваркових систем без заміни параметрів нерелятивістських потенціялів, що раніше успішно використовувались при нерелятивістських розрахунках спектра мас важких кваркових систем. 